\title{
Evolução dos retornos do investimento em educação no Brasil ao longo dos anos 2000
}

The educational investment return evolution in Brazil during the 2000s

\author{
Evolución de los retornos de la inversión en educación en Brasil a lo largo de \\ los años 2000
}

\section{Evolution des retours sur investissement dans l'éducation au Brésil au cours des années 2000}

\author{
Izete Pengo Bagolin ${ }^{1}$ \\ Nelson Juarez Lewis Ferraz Neto ${ }^{1}$
}

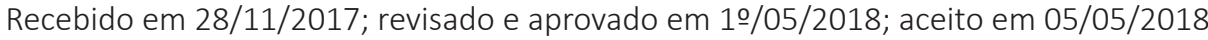

DOI: http://dx.doi.org/10.20435/inter.v0i0.1770

\begin{abstract}
Resumo: A educação é um tema relevante e atual, uma vez que, por meio dela, mudanças sociais positivas são possíveis. Com base nisso, este trabalho objetiva analisar a evolução dos retornos do investimento em educação no Brasil ao longo dos anos 2000. Para isso, foram utilizados os dados da Pesquisa de Orçamentos Familiares (POF) dos biênios 2002-2003 e 2008-2009. Os resultados mostram que o retorno da educação diminuiu ao longo do período, e as diferenças sociais entre cor, sexo e áreas urbana e rural permanecem presentes.
\end{abstract}

Palavras-chave: educação; investimento; mudanças sociais.

Abstract: Education is a relevant and current issue, since through it positive social changes are possible. Departing from that the aim of this paper it to analyze the educational investment return evolution in Brazil during the 2000s. For this purpose, we used the 2002-2003 and 2008-2009 biennial Household Budget Survey dataset. The aim is to contribute to the understanding of the effects of educational advances in the context of the reduction of income inequality. The results show that the return of education has decreased. In addition, the social differences between skin color, sex and in urban and rural areas remain present.

Keywords: education; investments; social changes.

Résumé: L'objectif de cette étude est d'analyser le comportement des retours sur investissement dans l'éducation au Brésil durant les années 2000. A cette fin, les données des POF biennaux 2002-2003 et 20082009 ont été utilisées. Les résultats montrent que le rendement de l'éducation a diminué au cours de la période et que les différences sociales entre la couleur, le sexe et les zones urbaines et rurales demeurent présentes.

Mots-clés: education; investissement; changements sociaux.

Resumen: Este trabajo tiene como objetivo analizar el comportamiento de los retornos de la inversión en educación, en Brasil a lo largo de los años 2000. Para ello se utilizaron los datos de las POFs de los bienios 2002-2003 y 2008-2009. Los resultados muestran que el retorno de la educación disminuyó a lo largo del período y las diferencias sociales entre color, sexo y áreas urbanas y rurales permanecen presentes.

Palabras clave: educación; inversión; cambios sociales.

\section{INTRODUÇÃO}

A educação é um dos temas que mais recebem destaque na sociedade, pois, por meio dela, é possível que ocorram mudanças sociais positivas, como melhor distribuição de renda, redução da pobreza e melhorias na qualidade de vida. Aos avanços educacionais são associados os aumentos no nível de renda dos países e os aumentos de produtividade, devido tanto pela qualificação da mão de obra quanto pela pesquisa e pelo desenvolvimento de novas tecnologias (MADURO JUNIOR, 2007). Além dos benefícios sociais que a educação proporciona, individualmente são

\footnotetext{
${ }^{1}$ Pontifícia Universidade Católica do Rio Grande do Sul (PUCRS), Porto Alegre, Rio Grande do Sul, Brasil.
} 
esperados retornos monetários e não monetários. Nessa perspectiva, pode-se calcular o retorno do investimento em educação, sendo este o objetivo deste trabalho. Essa abordagem mostra-se importante porque o indivíduo enfrenta um trade-off entre estudar um ano a mais, considerando o impacto que terá sobre sua renda futura, e os custos de oportunidade dessa decisão (LEAL; WERLANG, 1989).

No Brasil, os retornos do investimento em educação podem ser considerados elevados, visto que a média dos anos de estudo dos brasileiros ainda é baixa. Assim, pessoas que conseguem concluir níveis de ensino superiores acabam tendo prêmios por esse esforço adicional. Ao comparar as regiões Nordeste e Sudeste, Suliano e Siqueira (2012) concluíram que, na primeira região, onde a média de anos de estudo é inferior, os retornos são mais elevados do que na segunda. Há uma projeção de que, com o aumento da média de anos de estudo dos brasileiros, o retorno da educação diminua. Davanzo e Ferro (2016) alertam que uma possível queda nos retornos da educação pode estar relacionada a uma diminuição na qualidade do ensino, que por sua vez tem relação com a produtividade.

Ao estimar os retornos da educação no Brasil, deve-se considerar outros fatores além da relação direta entre salário e escolaridade. O fato de o mercado de trabalho brasileiro possuir desigualdades em relação aos salários, como, por exemplo, a diferença salarial entre homens e mulheres, exige que as características do indivíduo sejam controladas ao estimar os retornos da educação. Teixeira e Menezes-Filho (2012), Suliano e Siqueira (2012) e Leal e Werlang (1989) citam fatores como sexo, cor e local de residência dos indivíduos como exemplos de delimitação.

Em relação à diferença de salários entre sexos, a literatura mostra que os homens, em média, recebem mais do que as mulheres com a mesma escolaridade. De acordo com Leme e Wajnman (2000), essa diferença ocorre devido à discriminação no mercado de trabalho, sendo uma questão muitas vezes cultural. Dentre outros fatores não relacionados à produtividade, a discriminação pode ser comprovada pela diferença na média de anos de estudo, uma vez que, a partir do final da década de 1990, as mulheres passaram a ter média de anos de estudo superior à dos homens (SILVA; HASENBALG, 2000). Com base nesse dado e seguindo a lógica de que quanto maior a escolaridade mais elevado será o salário, as mulheres deveriam ter rendimentos superiores ao dos homens.

A discriminação por cor ou raça também está presente no mercado de trabalho brasileiro, visto que brancos possuem rendas superiores às dos não brancos (SULIANO; SIQUEIRA, 2012). Somado a isso, deve-se considerar a diferença histórica na média de anos de estudo, em que indivíduos não brancos frequentam a escola durante menos tempo quando comparados aos brancos (SILVA; HASENBALG, 2000).

Da mesma forma, a diferença entre as zonas urbana e rural afeta a renda dos indivíduos, pois as áreas urbanas, normalmente industrializadas, são mais ricas (BRANCO, 1979). Adicionalmente, a população rural possui escolaridade inferior à urbana, fato que se reflete na desigualdade de renda.

Outro aspecto que precisa ser considerado nas análises do retorno do investimento em educação é a experiência do indivíduo, visto que ela é uma variável consolidada na literatura, sendo que indivíduos mais velhos tendem a ocupar cargos mais elevados e com salários mais altos.

Neste artigo, busca-se explorar o comportamento do retorno do investimento em educação. Para isso, estima-se quanto cada ano de estudo a mais adiciona à renda dos indivíduos. Os dados utilizados neste trabalho são provenientes da Pesquisa de Orçamentos Familiares (POF), o 
que o diferencia de outras pesquisas relacionadas a esse tema, em sua maioria, que abordaram o tema utilizando os dados da Pesquisa Nacional por Amostra de Domicílios (PNAD).

O presente trabalho está dividido em cinco seções, considerando esta breve introdução. A segunda seção descreve a metodologia, apresentando as variáveis e o modelo utilizado para a estimação. A terceira seção é destinada às análises descritivas da base de dados. Na quarta seção, são apresentados e discutidos os resultados. Por fim, apresentam-se as considerações finais.

\section{METOdOLOGIA, APRESENTAÇÃO DAS VARIÁVEIS E O MODELO MQO}

Os dados utilizados neste artigo provêm da POF dos biênios 2002-2003 e 2008-2009. Para a variável Renda, foram somados os dez tipos de rendimentos individuais que a POF oferece. Esses rendimentos são caracterizados a partir da fonte que fornece a receita e podem ser provenientes das seguintes categorias: empregado, empregador, conta própria, aposentadoria pública, aposentadoria privada, bolsa de estudo, pensão alimentícia, mesada ou doação, transferências, rendimento de aluguel, dentre outros rendimentos.

Em relação à variável correspondente à educação, dentre as opções possíveis, foi escolhida a variável Anos de Estudo do morador. Esta, que é disponibilizada pelo Instituto Brasileiro de Geografia e Estatística (IBGE), teve uma mudança na sua criação no período entre as duas edições da POF. No biênio 2002-2003, os anos de estudo do indivíduo foram calculados a partir das variáveis Frequência à escola, Nível de escolaridade e Série que frequenta ou última concluída. Já no biênio 2008-2009, além das variáveis utilizadas, foram acrescentadas a Duração do curso de primeiro grau e o Curso mais elevado que frequentou. Antecipando a apresentação dos dados descritivos, essa mudança na formação da variável fará com que o número máximo encontrado na POF 2002-2003 seja de 17 anos, enquanto que, na de 2008-2009, é de 15 anos. Por conta de ser pequena a parcela da população que tem o número máximo de anos de estudo, essa diferença não é significativa para os objetivos deste trabalho.

As variáveis de controle são: idade, experiência, sexo, cor ou raça e local de residência. Em relação à idade, foram selecionadas apenas pessoas entre 24 e 65 anos. A experiência é calculada a partir da idade ao quadrado, como realizado por Leal e Werlang (1989), Suliano e Siqueira (2012) e Teixeira e Menezes-Filho (2012). Além de idade e experiência, foram utilizadas as variáveis sexo, cor ou raça, zona de residência (se urbana ou rural) e variáveis geográficas.

O Quadro 1, a seguir, contém as variáveis Urbano ou rural, Sexo e Cor ou raça e como elas se apresentam na regressão. As variáveis selecionadas foram convenientemente utilizadas em trabalhos que estimam o retorno da educação. Idade e Experiência, por exemplo, são as únicas variáveis acrescentadas na pesquisa realizada por Leal e Werlang (1989) para explicar a relação entre educação e salário. A equação que os autores utilizaram pode ser considerada simplificada, visto que não considera algumas desigualdades presentes no mercado de trabalho brasileiro. Idade e Experiência também foram consideradas por Suliano e Siqueira (2012) e Teixeira e Menezes-Filho (2012). 
Quadro 1 - Descrição das variáveis na regressão

\begin{tabular}{|c|c|}
\hline Variável & Valor na regressão \\
\hline \multirow{2}{*}{ Urbano ou rural } & Urbano $=1$ \\
\cline { 2 - 2 } & Rural $=0$ \\
\hline \multirow{2}{*}{ Sexo } & Homem $=1$ \\
\cline { 2 - 2 } Cor ou raça & Mulher $=0$ \\
\cline { 2 - 2 } & Branco $=1$ \\
\hline \multirow{2}{*}{ Não Branco $=0$} \\
\hline
\end{tabular}

Fonte: Os autores (2018), com base em IBGE (2004; 2010).

Suliano e Siqueira (2012) buscaram medir, principalmente, a taxa de retorno da educação entre as regiões Nordeste e Sudeste, visto que estas são regiões heterogêneas, entre outras questões, no sentido de renda e desigualdade. Além das duas regiões, os autores consideraram as diferenças entre a população que vive em áreas urbanas e a que mora na zona rural. Outra variável utilizada por eles considera que as desigualdades existentes no Brasil têm relação com a cor ou raça do indivíduo.

Já Teixeira e Menezes-Filho (2012) assumiram as desigualdades regionais considerando a educação do indivíduo, sem relacioná-las diretamente com a renda, e identificaram que as diferenças regionais afetam a educação da população. Nos estados em que a educação é oferecida em maior quantidade e com mais qualidade, por consequência, ela irá diferenciar os salários obtidos. Além disso, os autores consideraram as diferenças existentes entre homens e mulheres em relação ao salário.

Após a apresentação das variáveis, cabe apresentar o modelo econométrico a ser estimado. Para analisar o retorno da educação sobre o salário, escolheu-se utilizar uma regressão múltipla por meio do método dos Mínimos Quadrados Ordinários (MQO). Cabe informar que a variável dependente foi utilizada em sua forma logarítmica (WOOLDRIDGE, 2011). Com isso, será estimada a proporção na qual as variáveis independentes afetam a dependente, seguindo este modelo:

$$
\operatorname{In}(w)=\beta_{0}+\beta_{1} A E+\beta_{2} I d+\beta_{3} \operatorname{Exp}+\beta_{4} \text { Area }+\beta_{5} \text { Sexo }+\beta_{6} \text { Cor }+D_{i} \text { Est }+\in \text { idade }^{2}
$$

Onde:

$w=$ renda

$A E=$ anos de estudo

id $=$ idade

$\exp =i d a d e^{2}$

Área = urbano ou rural

sexo $=$ sexo

cor = cor ou raça

dummies de estado $=R O, A C, A M, R R, P A, A P, T O, M A, P I, C E, R N, P B, P E, A L, S E, B A, E S, R J, S P$, $\mathrm{PR}, \mathrm{SC}, \mathrm{RS}, \mathrm{MS}, \mathrm{MT}, \mathrm{GO}, \mathrm{DF}$.

constante = variável constante representando MG 


\section{ANÁLISE DESCRITIVA}

As estatísticas descritivas das variáveis utilizadas na regressão, exceto as dummies de estado, são apresentadas na Tabela 1, a seguir. O número de observações selecionadas na POF de 2002-2003 foi de 64.308, e na de 2008-2009 foi de 75.851 .

A renda total média anual dos brasileiros era de $\mathrm{R} \$$ 9.394,75, na edição de 2002-2003; e de $\mathrm{R} \$ 13.531,41$, na edição de 2008-2009. Tendo em vista que o objetivo deste trabalho é analisar o retorno do investimento em educação na renda, e não a evolução da renda, utilizaram-se valores nominais. É possível observar que $75 \%$ da população tinha uma renda anual de $\mathrm{R} \$ 8.822,82$, em 2002-2003, e R\$13.690,90, em 2008-2009. Isso significa que, na primeira edição observada, três quartos da população tinha uma renda abaixo da média, enquanto que, na edição posterior, a renda dessa população ficou um pouco acima da média.

Já as médias dos anos de estudo ficaram em 6 e 7 anos entre 2002-2003 e 2008-2009, respectivamente. A diferença no máximo apresentado entre as edições deve-se à metodologia utilizada pelo IBGE para a criação dessa variável. Como é possível observar, parte da população foi contabilizada com 17 anos de estudo em 2002-2003, mesmo assim a média nesse período foi inferior à edição posterior.

Para a variável Urbano e rural, é possível notar que o percentual que reside em cidades permaneceu constante em 78\%. Em relação ao sexo, na POF de 2002-2003, 56,61\% da amostra era masculina, enquanto que na de 2008-2009 diminuiu para 53,97\%. Por fim, 43,89\% da população foi considerada branca na primeira edição, enquanto que na edição seguinte esse número caiu para $41,10 \%$.

Tabela 1 - Dados descritivos

\begin{tabular}{c|c|c|c|c|c}
\hline Variáveis & Período & Média & Desvio padrão & Mínimo & Máximo \\
\hline \multirow{2}{*}{ Renda total } & $2002-2003$ & 9394,75 & 27333.1 & 4.95 & 4616108 \\
& $2008-2009$ & 13531,41 & 24529,24 & 3.51 & 1085580 \\
\multirow{4}{*}{ Anos de estudo } & $2002-2003$ & 6,12 & 4.644 .427 & 0 & 17 \\
& $2008-2009$ & 7,19 & 4.592 .793 & 0 & 15 \\
Idade & $2002-2003$ & 40,75 & 1.121 .223 & 24 & 65 \\
& $2008-2009$ & 41,36 & 1.144 .147 & 24 & 65 \\
Idade 2 & $2002-2003$ & 1786,61 & 9.703 .796 & 576 & 4225 \\
\multirow{3}{*}{ Urbano } & $2008-2009$ & 1812,29 & 9.954 .224 & 576 & 4225 \\
& $2002-2003$ & 0,78 & .4112755 & 0 & 1 \\
Sexo & $2008-2009$ & 0,7804 & .4139169 & 0 & 1 \\
& $2002-2003$ & 0,5661 & .4956232 & 1 & 2 \\
Cor ou raça & $2008-2009$ & 0,5397 & .4984308 & 1 & 2 \\
& $2002-2003$ & 0,4389 & .4962551 & 1 & 2 \\
\hline
\end{tabular}

Fonte: Os autores (2018), com base em IBGE (2004; 2010).

A seguir, serão apresentados os dados referentes à média de anos de estudo dos indivíduos segundo as variáveis Sexo, Cor ou raça e Urbano ou rural, para observar suas diferenças. Também foram separados os números de observações das variáveis escolhidas. Novamente foram utilizadas as duas edições da POF, conforme mostra a Tabela 2, a seguir. 
A primeira variável apresentada refere-se ao sexo, sendo que a quantidade de homens é superior à de mulheres nas duas edições da POF. A média de anos de estudo dos homens é menor do que a das mulheres nos dois biênios. Essa diferença, que em 2002-2003 era de quase um ano, ficou praticamente constante. Porém, ao comparar esses dados com os do trabalho realizado por Silva e Hasenbalg (2000), é possível notar que, em média, as mulheres tiveram uma evolução considerável perante os homens em relação aos anos de estudo entre 1998 e 2009. Segundo os autores, as mulheres estudavam 0,2 anos a mais que os homens em 1998, passando a ser 0,78 em 2008-2009, chegando perto de um ano de diferença. Deve-se ressaltar que os dados utilizados por Silva e Hasenbalg (2000) foram coletados de forma e de bases diferentes, mesmo assim a diferença encontrada é significativa.

Ao observar a variável Cor ou raça, é possível notar que ainda há uma diferença significativa no número de anos de estudo entre brancos e não brancos, sendo que essa diferença chega a quase dois anos. Ao comparar novamente a Tabela 2 com o trabalho de Silva e Hasenbalg (2000), é notável que, entre 1998 e 2008-2009, a diferença teve uma queda, mas ainda pequena. Enquanto que em 1998, segundo os autores, a população não branca estudava 2,1 anos a menos que a branca, essa diferença caiu para 1,8 em 2008-2009.

Por fim, ao comparar a população da área urbana com a não urbana, as médias dos anos de estudo são bem superiores para a área urbana. A diferença entre as áreas urbana e rural é a mais elevada entre as variáveis que foram observadas, chegando a mais de três anos nos dois biênios. Essa diferença é esperada, visto que é consenso que a estrutura educacional na área rural é mais precária, além da dificuldade do acesso às escolas por parte dos alunos e professores e da falta de incentivo na permanência de professores, o que causa rotatividade (INEP, 2007).

Tabela 2 - Média de anos de estudo

\begin{tabular}{ccccc}
\hline Variáveis & Período & Anos de estudo & Observações \\
\hline \multirow{2}{*}{ Homem } & $2002-2003$ & 5,77 & 36401 \\
& $2008-2009$ & 6,84 & 40931 \\
Mulher & $2002-2003$ & 6,58 & 27907 \\
& $2008-2009$ & 7,62 & 34920 \\
Branco & $2002-2003$ & 7,16 & 28224 \\
& $2008-2009$ & 8,27 & 31171 \\
Não branco & $2002-2003$ & 5,32 & 36084 \\
\multirow{2}{*}{ Urbano } & $2008-2009$ & 6,45 & 44680 \\
\multirow{3}{*}{ Não urbano } & $2002-2003$ & 6,83 & 50440 \\
& $2008-2009$ & 7,93 & 59201 \\
& $2002-2003$ & 3,65 & 13868 \\
\hline
\end{tabular}

Fonte: Os autores (2018), com base em IBGE (2004; 2010). 


\section{RESULTADOS ESTIMADOS}

Após os dados descritivos terem sido apresentados na seção anterior, cabe agora analisar os resultados das estimações ${ }^{2}$.

A Tabela 3, a seguir, apresenta os resultados da regressão do modelo MQO com as variáveis explicativas e variável dummies utilizada para os períodos 2002-2003 e 2008-2009. Primeiramente, a análise será focada nas variáveis anos de estudo, idade, experiência, urbano, sexo e cor ou raça. Posteriormente, será voltada para as dummies de estado. É importante ressaltar que, no modelo, a variável dependente é logarítmica e que os resultados da regressão irão identificar o quanto que as variáveis independentes impactam percentualmente na renda.

Ao observar a Tabela 3, é possível identificar os coeficientes estimados no modelo MQO, abaixo de cada coeficiente encontra-se o erro padrão entre parênteses, e os asteriscos evidenciam o respectivo nível de confiança. A primeira variável a ser analisada refere-se aos anos de estudo. Como era esperado, o aumento de um ano de estudo acarreta em crescimento do salário. Para o biênio 2002-2003, um ano a mais de estudo equivale a um retorno de 14,09\% no salário, enquanto que para 2008-2009 o prêmio para cada ano a mais de estudo cai para 12,07\%. Esses valores são semelhantes aos encontrados por Teixeira e Menezes-Filho (2012) e Leal e Werlang (1989), que encontraram, respectivamente, retornos de $11,60 \%$ e 15,50\%.

Suliano e Siqueira (2012) calcularam retornos de 16\% na região Nordeste e de $13 \%$ na Sudeste. As diferenças nos resultados encontrados entre os outros trabalhos e a regressão feita neste podem estar atreladas ao fato de que as bases de dados e os períodos utilizados são diferentes. Entretanto é possível observar certa semelhança, visto que os números estão próximos. Além disso, ao observar os resultados encontrados por Suliano e Siqueira (2012), é possível encontrar uma explicação para a queda dos retornos da Tabela 3 entre 2002-2003 e 2008-2009. O trabalho realizado pelos autores mostra maiores retornos da educação na região Nordeste quando comparada à Sudeste.

Segundo Suliano e Siqueira (2012), os maiores retornos no Nordeste estão relacionados à média de anos de estudo das regiões, visto que em 2006, no Nordeste, a média era de seis anos e, no Sudeste, de oito anos. Com isso, à medida que uma população tem média de anos de estudo inferior, o acréscimo de um ano de estudo fica mais valioso. Introduzindo essa conclusão nos dados das Tabelas 2, que contém a média de anos de estudo, e 3, que contém o retorno da educação, é possível encontrar resultados semelhantes. No biênio 2002-2003, a média de anos de estudo era de seis anos, enquanto que para 2008-2009 passou a ser nove anos. Logo, o prêmio por um ano a mais de estudo ficou menor em 2008-2009 por conta da oferta de pessoas com mais anos de estudo.

Davanzo e Ferro (2016) concluíram que o aumento de anos de estudo tem dado retornos cada vez menores em relação à renda. As autoras observaram que, ao completar níveis de ensino, como o fundamental e o médio, a diferença do acréscimo na renda entre eles está diminuindo. Porém argumentam que a queda nos retornos pode estar relacionada à queda da produtividade, que, por sua vez, é refletida pela diminuição na qualidade do ensino.

\footnotetext{
${ }^{2}$ Para fins ilustrativos, nas Tabelas A.1 e A.2 do Apêndice A são disponibilizadas as correlações entre renda e as variáveis observadas para os biênios 2002-2003 e 2008-2009, respectivamente. Nos dois períodos, a correlação tem o mesmo sinal, em que anos de estudo, idade e experiência têm impacto positivo na renda. A variável Urbano e rural mostra que indivíduos que moram em áreas urbanas recebem mais do que quem vive em áreas rurais. Já a variável Sexo evidencia que mulheres recebem menos que homens. Por fim, a variável Cor ou raça mostra que não brancos recebem menos do que brancos.
} 
Essa queda no retorno da educação sobre a renda em 2008-2009 pode ser vista como queda na desigualdade de renda. Segundo Leal e Werlang (1990, p. 11): "Um aumento do retorno pessoal em educação, em geral, significa um aumento na desigualdade da distribuição de renda". É possível concluir que a diferença da renda, em 2008-2009, para quem tivesse apenas o Ensino Fundamental e outra pessoa com Ensino Médio, passou a ser menor do que em 2002-2003.

$\mathrm{O}$ aumento da idade também afeta de forma positiva a renda. Entretanto a variação entre os períodos não foi tão grande quanto nos anos de estudo. Um ano de idade a mais representava um acréscimo de 5,78\% na renda em 2002-2003 e de 5,23\% em 2008-2009. Pessoas com mais idade tendem a possuir maiores rendas por conta de adquirirem mais experiência ao longo do tempo. Além disso, pessoas mais velhas tendem a ter ciclos de educação mais completo, o que resulta em um aumento da renda (TEIXEIRA; MENEZES-FILHO, 2012).

Todavia, ao argumentar que o aumento da idade ocasiona numa maior renda por conta da experiência, é preciso ressaltar que esse aumento vai ocorrendo a taxas decrescentes (TEIXEIRA; MENEZES-FILHO, 2012), ou seja, quanto mais velho o indivíduo fica, menor será o retorno da sua idade adicional. Isso pode ser confirmado através da variável experiência encontrada na Tabela 3.

Continuando a análise das variáveis de controle, na variável Urbana ou rural foi encontrado que quem reside em áreas urbanas recebe salários maiores de quem vive em áreas rurais. Para o biênio 2002-2003, os salários de quem vive em áreas urbanas era cerca de 30\% maiores, enquanto que esse valor cai para 21,59\% em 2008-2009. O fato de a renda ser maior em áreas urbanas já era esperado, tendo em vista que áreas industrializadas, normalmente urbanas, possuem rendas mais elevadas do que as rurais (BRANCO, 1979). Além disso, heterogeneidades entre os trabalhadores de áreas urbanas e rurais é outro fator que influencia no salário (BARROS; MENDONÇA, 1995). Essa heterogeneidade entre os trabalhadores urbanos e rurais pode ser vista entre os anos de estudo, conforme mostra a Tabela 2, em que os primeiros possuem quase oito anos, e os segundos, menos de cinco anos.

No que diz respeito ao nível de pobreza de cada área como uma forma alternativa de medir a renda da população, é possível confirmar que áreas urbanas são mais ricas que as rurais. Considerando que pessoas abaixo da linha da pobreza recebem menos do que $R \$ 140,00$, em 2010, 40\% da população na área rural estava abaixo da linha da pobreza, enquanto que, em áreas urbanas, esse valor é de 17\% (BAGOLIN; MATTOS, 2014).

A variável Sexo mostra que as mulheres recebiam salários cerca de $67,82 \%$ a menos que os homens em 2002-2003, sendo que essa diferença aumentou para 58,83\% em 2008-2009. Segundo Leme e Wajnman (2000, p. 251), que também constataram essa diferença em sua pesquisa, isso ocorre, principalmente, devido "[...] à discriminação (salarial ou alocativa) e não às diferenças de produtividade [...]". Ou seja, homens recebem mais por conta da discriminação, e não por terem maiores habilidades. As palavras das autoras se confirmam quando se observa a média de anos de estudo encontrada na Tabela 2, que mostra que as mulheres possuem maior tempo estudado que os homens. Se for levado em conta que anos de estudo é uma medida de habilidade, é possível concluir que o mercado de trabalho diferencia os gêneros não por conta de sua produtividade, e sim por uma questão discriminatória. 
Tabela 3 - Fatores que afetam a renda

\begin{tabular}{|c|c|c|c|c|c|}
\hline Variáveis & 2002-2003 & 2008-2009 & Variáveis & 2002-2003 & 2008-2009 \\
\hline $\begin{array}{l}\text { Anos de } \\
\text { estudo }\end{array}$ & $\begin{array}{c}.1409048 \\
(.00099)^{* * *}\end{array}$ & $\begin{array}{c}.1207696 \\
(.0008398)^{* * *}\end{array}$ & PB & $\begin{array}{c}-0.3833076 \\
(.0247115)^{* * *}\end{array}$ & $\begin{array}{c}-0.2756029 \\
(.0230628)^{* * *}\end{array}$ \\
\hline Idade & $\begin{array}{c}.0578779 \\
(.0028515)^{* * *}\end{array}$ & $\begin{array}{c}.0523255 \\
(.0023521)^{* * *}\end{array}$ & PE & $\begin{array}{c}-0.3490389 \\
(.0266448)^{* * *}\end{array}$ & $\begin{array}{c}-0.3204308 \\
(.0199022)^{* * *}\end{array}$ \\
\hline Experiência & $\begin{array}{c}-0.0003878 \\
(.000033)^{* * *}\end{array}$ & $\begin{array}{c}-0.0003241 \\
(.000027)^{* * *}\end{array}$ & $A L$ & $\begin{array}{c}-0.3014485 \\
(.0232015)^{* * *}\end{array}$ & $\begin{array}{c}-0.3354819 \\
(.0193132)^{* * *}\end{array}$ \\
\hline $\begin{array}{l}\text { Urbana ou } \\
\text { rural }\end{array}$ & $\begin{array}{c}.3012585 \\
(.0106903)^{* * *}\end{array}$ & $\begin{array}{c}.215923 \\
(.0087419)^{* * *}\end{array}$ & BA & $\begin{array}{c}-0.2607505 \\
(.0240839)^{* * *}\end{array}$ & $\begin{array}{c}-0.3421125 \\
(.0181186)^{* * *}\end{array}$ \\
\hline Sexo & $\begin{array}{c}0.6782395 \\
(.0083409)^{* * *}\end{array}$ & $\begin{array}{c}0.5883847 \\
(.0068486)^{* * *}\end{array}$ & SE & $\begin{array}{c}-0.2784225 \\
(0.0310906)^{* * *}\end{array}$ & $\begin{array}{c}-0.1799168 \\
(0.225849)^{* * *}\end{array}$ \\
\hline Cor ou raça & $\begin{array}{c}0.1592668 \\
(.0091026)^{* * *}\end{array}$ & $\begin{array}{c}0.1437808 \\
(.0075952)^{* * *}\end{array}$ & ES & $\begin{array}{c}.088749 \\
(.0242613)^{* * *}\end{array}$ & $\begin{array}{c}-0.074853 \\
(.0177587)^{* * *}\end{array}$ \\
\hline RO & $\begin{array}{c}.2278349 \\
(.031716)^{* * *}\end{array}$ & $\begin{array}{c}.0435439 \\
(.0294793)\end{array}$ & RJ & $\begin{array}{c}.0535158 \\
(.0298075)^{*}\end{array}$ & $\begin{array}{c}.0257021 \\
(.0216662)\end{array}$ \\
\hline$A C$ & $\begin{array}{c}.1178217 \\
(.0356152)^{* * *}\end{array}$ & $\begin{array}{c}-0.087052 \\
(.0292268)^{* * *}\end{array}$ & SP & $\begin{array}{c}.3499255 \\
(.0252717)^{* * *}\end{array}$ & $\begin{array}{c}.1901899 \\
(.0173643)^{* * *}\end{array}$ \\
\hline AM & $\begin{array}{c}-0.1827626 \\
(.0333069)^{* * *}\end{array}$ & $\begin{array}{c}-0.2108288 \\
(.0249703)^{* * *}\end{array}$ & PR & $\begin{array}{c}.1986244 \\
(.0248471)^{* * *}\end{array}$ & $\begin{array}{c}.0630464 \\
(.0198482)^{* * *}\end{array}$ \\
\hline $\mathrm{RR}$ & $\begin{array}{r}-0.0602086 \\
(.0416198)\end{array}$ & $\begin{array}{c}-0.1264806 \\
(.0344759)^{* * *}\end{array}$ & SC & $\begin{array}{c}.178828 \\
(.025943)^{* * *}\end{array}$ & $\begin{array}{c}.0961775 \\
(.0210377)^{* * *}\end{array}$ \\
\hline PA & $\begin{array}{l}.0071176 \\
(.0272415)\end{array}$ & $\begin{array}{c}-0.1125919 \\
(.0212653)^{* * *}\end{array}$ & RS & $\begin{array}{c}.0276879 \\
(.0264316)\end{array}$ & $\begin{array}{c}.0455948 \\
(.020596)^{* *}\end{array}$ \\
\hline$A P$ & $\begin{array}{c}-0.1692063 \\
(.0424567)^{* * *}\end{array}$ & $\begin{array}{c}.0992058 \\
(.0327987)^{* * *}\end{array}$ & MS & $\begin{array}{c}.091784 \\
(.0243188)^{* * *}\end{array}$ & $\begin{array}{c}.1164912 \\
(.0204455)^{* * *}\end{array}$ \\
\hline TO & $\begin{array}{c}-0.3264752 \\
(.0349469)^{* * *}\end{array}$ & $\begin{array}{c}-0.1540425 \\
(.0249827)^{* * *}\end{array}$ & MT & $\begin{array}{c}.103037 \\
(.0250825)^{* * *}\end{array}$ & $\begin{array}{c}.040278 \\
(.0204093)^{* *}\end{array}$ \\
\hline MA & $\begin{array}{c}-0.3118922 \\
(.0251031)^{* * *}\end{array}$ & $\begin{array}{c}-0.2944263 \\
(.0197483)^{* * *}\end{array}$ & GO & $\begin{array}{c}.0718485 \\
(.0246773)^{* * *}\end{array}$ & $\begin{array}{c}.0744538 \\
(.0195799)^{* * *}\end{array}$ \\
\hline $\mathrm{Pl}$ & $\begin{array}{c}-0.3324234 \\
(.0244944)^{* * *}\end{array}$ & $\begin{array}{c}-0.426533 \\
(.0203027)^{* * *}\end{array}$ & DF & $\begin{array}{c}.4704998 \\
(.0334716)^{* * *}\end{array}$ & $\begin{array}{c}.2082083 \\
(.0281664)^{* * *}\end{array}$ \\
\hline CE & $\begin{array}{c}-0.397188 \\
(.0250523)^{* * *}\end{array}$ & $\begin{array}{c}-0.4203293 \\
(.0217901)^{* * *}\end{array}$ & Constante & $\begin{array}{c}6.815501 \\
(.0636723)^{* * *}\end{array}$ & $\begin{array}{c}7.439106 \\
(.0532602)^{* * *}\end{array}$ \\
\hline RN & $\begin{array}{c}-0.1803188 \\
(.0281232)^{* * *}\end{array}$ & $\begin{array}{c}-0.3400811 \\
(.0243839)^{* * *}\end{array}$ & & & \\
\hline 2002-2003: & $R=0,3908$ & $R^{2}=0,3905$ & 2008-2009: & $R=0,3606$ & $R^{2}=0,3604$ \\
\hline
\end{tabular}

Fonte: Os autores (2018), com base em IBGE (2004; 2010).

Da mesma forma, a variável Cor ou raça mostra uma discriminação do mercado de trabalho (SULIANO; SIQUEIRA, 2012). Indivíduos não brancos recebiam 15,92\% a menos que brancos em 2002-2003, tendo esse valor aumentado para 14,37\% em 2008-2009. Além da discriminação, indivíduos não brancos possuem uma média de anos de estudo bem inferior à dos brancos, como é possível observar na Tabela 2. A menor média de anos de estudo pode estar relacionada à diferença salarial.

Por fim, é necessário analisar as dummies de estado. Há algumas variáveis que não são significativas ao modelo, sendo que, entre os biênios, algumas variáveis possuem diferentes 
significâncias. Para 2002-2003, as variáveis não significativas são RR, PA e RS, enquanto que, em 2008-2009, são RO e RJ, por isso esses estados não foram analisados no período que não tiveram significância. Lembrando que a constante é o estado de Minas Gerais.

Nos resultados encontrados, cabe destacar que em 2002-2003 os indivíduos residentes em Rondônia tiveram em média salários superiores aos de Minas Gerais. Em contrapartida, os outros estados da região Norte tiveram resultados contrários ao de Rondônia, com renda menor que a de Minas Gerais. Em 2008-2009, foi a vez de o Amapá surpreender, tendo sua população uma renda maior do que Minas Gerais.

Para os estados da região Nordeste, os resultados não demonstraram surpresa ao apresentarem que todos os estados possuem rendas inferiores às de Minas Gerais, sendo que a menor renda para os estados do Nordeste valeu para os dois períodos observados. Esse resultado condiz com o encontrado em outros trabalhos.

Ao comparar Minas Gerais com os outros estados da região Sudeste, em 2002-2003 é possível observar que a renda da Constante é inferior a todos os seus vizinhos. São Paulo, como esperado, é um dos que apresentam renda maior do que Minas Gerais. Já em 2008-2009, indivíduos residentes no Espírito Santo passaram a ter renda inferior. Em comparação aos estados das regiões Centro-Oeste e Sul, a renda dos mineiros é inferior a todos os estados dessas regiões, sendo que a maior diferença é com o Distrito Federal.

Depois de observar a Tabela 3, é possível concluir que o retorno do investimento em educação vem diminuindo. Primeiramente, porque o retorno do investimento em educação pode estar caindo por conta do aumento da média de anos de estudo que vem ocorrendo no Brasil. Davanzo e Ferro (2016) argumentam que a queda da produtividade dos trabalhadores faz com que o retorno do investimento em educação diminua. Além disso, foi visto que as desigualdades de renda entre urbano e rural, sexos e cor se mantêm, ocorrendo, principalmente, em razão da discriminação.

\section{CONSIDERAÇÕES FINAIS}

O presente trabalho permitiu observar que o acréscimo na renda por ano adicional de estudo está diminuindo, sendo que em 2002-2003 um ano a mais de estudo representava um aumento de $14,09 \%$ na renda, enquanto que para 2008-2009 esse valor caiu para $12,07 \%$. Uma das possíveis explicações para essa queda é o fato de o crescimento da média de anos de estudo no Brasil permitir a oferta de trabalhadores com maior escolaridade no mercado de trabalho, o que faz com que os salários fiquem mais nivelados. Por exemplo, em 2008-2009, o número de pessoas que concluíram o Ensino Médio era consideravelmente superior ao de 2002-2003, visto que a média de anos de estudo entre os dois períodos aumentou mais de um ano. Esse resultado foi encontrado também por Davanzo e Ferro (2016), mas, segundo elas, o motivo seria a diminuição da produtividade dos trabalhadores.

Ademais, foram encontradas diferenças em relação à renda entre sexo, cor ou raça e entre áreas urbanas e rurais. Em relação ao sexo, identificou-se que os homens ainda recebem mais do que as mulheres, apesar de as mulheres possuírem média de anos de estudo superior à dos homens, e essa média vem mostrando tendência de aumento. O argumento encontrado para esse resultado é a discriminação de gênero ainda existente no mercado de trabalho. Quanto à cor ou raça, brancos recebem mais do que não brancos, sobretudo em razão da discriminação racial, além de que indivíduos não brancos ainda possuem uma média de anos de estudo bem 
inferior à dos brancos. Para as áreas urbanas e rurais, foi visto que indivíduos que residem em áreas urbanas recebem mais do que os de áreas rurais, pois os primeiros possuem média de anos de estudo bem superiores aos segundos. Somado a isso, em áreas industrializadas os salários são maiores do que em áreas rurais (BRANCO, 1979).

\section{REFERÊNCIAS}

BAGOLIN, Izete Pengo; MATTOS, Ely José de. A evolução da pobreza no Rio Grande do Sul entre 2000 e 2010. In: BAGOLIN, Izete Pengo; MATTOS, Ely José de. Desenvolvimento econômico no Rio Grande do Sul: já não somos o que éramos? Porto Alegre: EDIPUCRS, 2014. p. 203-19.

BARROS, Ricardo Paes; MENDONÇA, Rosane Silva Pinto. Os determinantes da desigualdade no Brasil. Rio de Janeiro: IPEA, 1995. Disponível em: http://www.ipea.gov.br/portal/images/stories/PDFs/TDs/td_0377. pdf. Acesso em: 3 out. 2016.

BRANCO, Roberto Castello. Crescimento acelerado e o mercado de trabalho: a experiência brasileira. Revista Brasileira de Economia, Rio de Janeiro, v. 33, n. 2, p. 247-86, 1979.

DAVANZO, Eloá Sales; FERRO, Andrea Rodrigues. Retornos à educação: uma análise da redução do diferencial salarial por anos de estudo no Brasil no período de 2001 a 2012. 2016. Disponível em: https://www.anpec. org.br/sul/2016/submissao/files_1/i2-c8df9b0eb400991c63fabcda38ea8713.pdf. Acesso em: 14 nov. 2017.

INSTITUTO BRASILEIRO DE GEOGRAFIA E ESTATÍSTICA (IBGE). Pesquisa de Orçamentos Familiares 20082009. Despesas, rendimentos e condições de vida. Rio de Janeiro: IBGE, 2010. Disponível em: https:// biblioteca.ibge.gov.br/visualizacao/livros/liv45130.pdf. Acesso em: 3 out. 2016.

INSTITUTO BRASILEIRO DE GEOGRAFIA E ESTATÍSTICA (IBGE). Pesquisa de Orçamentos Familiares 20022003. Primeiros resultados - Brasil e grandes regiões. 2. ed. Rio de Janeiro: IBGE, 2004. Disponível em: https://biblioteca.ibge.gov.br/visualizacao/livros/liv81847.pdf. Acesso em: 3 out. 2016.

INSTITUTO NACIONAL DE ESTUDOS E PESQUISAS EDUCACIONAIS ANÍSIO TEIXEIRA (INEP). Sinopse estatística da educação básica: censo escolar 2006. Brasília: O Instituto, 2007. Disponível em: http://portal.inep.gov. br/documents/186968/484421/Sinopse+estat\%C3\%ADstica+da+educa\%C3\%A7\%C3\%A3o+b\%C3\%A1sic a+censo+escolar+2006/9dc9b493-ff6f-4649-a4e9-f4b2b9510831?version=1.2. Acesso em: 3 out. 2016.

LEAL, Carlos Ivan Simonsen; WERLANG, Sérgio Ribeiro da Costa. Educação e distribuição de renda. 1990. Disponível em: http://bibliotecadigital.fgv.br/dspace/bitstream/handle/10438/534/150_000054866. pdf? sequence=1\&isAllowed=y. Acesso em: 14 nov. 2015.

LEAL, Carlos Ivan Simonsen; WERLANG, Sérgio Ribeiro da Costa. Retornos em educação no Brasil: 1976-1986. 1989. Disponível em: http://bibliotecadigital.fgv.br/dspace/bitstream/handle/10438/651/148_000052262. pdf? sequence=1\&isAllowed=y. Acesso em: 4 nov. 2015.

LEME, Maria Carolina da Silva; WAJNMAN, Simone. Tendências de coorte nos diferenciais de rendimentos por sexo. In: HENRIQUES, R. (Org.). Desigualdade e pobreza no Brasil. Rio de Janeiro: IPEA, 2000. p. 251-70.

MADURO JUNIOR, Paulo Rogério Rodrigues. Taxa de matrícula e gastos em educação no Brasil. Orientador: Samuel de Abreu Pessoa. 2007. 42 f. Dissertação (Mestrado em Economia) - Escola de Pós-Graduação em Economia, Fundação Getulio Vargas, Rio de Janeiro, 2007. Disponível em: http://bibliotecadigital.fgv. $\mathrm{br} / \mathrm{dspace} / \mathrm{bitstream} /$ handle/10438/110/2284. pdf;jsessionid=0336BBC3281B745B2D17605E598AEB30 ?sequence=1. Acesso em: 4 nov. 2015.

SILVA, Nelson do Valle; HASENBALG, Carlos. Tendências da desigualdade educacional no Brasil. Dados, Rio de Janeiro, v. 43, n. 3, 2000. 
SULIANO, Daniel Cirilo; SIQUEIRA, Marcelo Lettieri. Retornos da educação no Brasil em âmbito regional considerando um ambiente de menor desigualdade. Economia Aplicada, v. 16, n: 1, p. 137-65, 2012.

TEIXEIRA, Wladimir Machado; MENEZES-FILHO, Naércio Aquino. Estimando o retorno à educação do Brasil considerando a legislação educacional brasileira como um instrumento. Revista de Economia e Política, v. 32, n. 3, p. 479-96, 2012.

WOOLDRIDGE, Jeffrey Marc. O modelo de regressão simples. In: WOOLDRIDGE, Jeffrey Marc. Introdução à econometria: uma abordagem moderna. 4. ed. São Paulo: Thomson, 2011. p. 20-62.

\section{APÊNDICE - CORRELAÇÃO ENTRE AS VARIÁVEIS OBSERVADAS}

Tabela 1 - Correlação entre variáveis da POF de 2002-2003

\begin{tabular}{lccccccc}
\hline & Renda total & $\begin{array}{c}\text { Anos de } \\
\text { estudo }\end{array}$ & Idade & idade $^{2}$ & $\begin{array}{c}\text { Urbano } \\
\text { ou rural }\end{array}$ & Sexo & $\begin{array}{c}\text { Cor ou } \\
\text { raça }\end{array}$ \\
\hline Renda Total & 1 & & & & & & \\
Anos de estudo & 0.2632 & 1 & & & & & \\
Idade & 0.0547 & $-0,2488$ & 1 & & & & \\
Experiência & 0.0473 & $-0,2547$ & 0.9917 & 1 & & & \\
Urbano ou rural & 0.0663 & 0.2907 & $-0,0544$ & $-0,058$ & 1 & & \\
Sexo & 0,0802 & -0.0870 & -0.0220 & -0.0228 & $-0,0766$ & 1 & \\
Cor ou raça & 0,1042 & 0,1968 & 0,042 & 0,0416 & 0,0447 & 0,0076 & 1 \\
\hline
\end{tabular}

Fonte: Os autores (2018), com base em IBGE (2004; 2010).

Tabela 2 - Correlação entre variáveis da POF de 2008-2009

\begin{tabular}{lccccccc}
\hline & Renda total & $\begin{array}{c}\text { Anos de } \\
\text { estudo }\end{array}$ & Idade & idade $^{2}$ & $\begin{array}{c}\text { Urbano } \\
\text { ou rural }\end{array}$ & Sexo & $\begin{array}{c}\text { Cor ou } \\
\text { raça }\end{array}$ \\
\hline Renda Total & 1 & & & & & & \\
Anos de estudo & 0.3356 & 1 & & & & & \\
Idade & 0.0826 & $-0,2974$ & 1 & & & & \\
Experiência & 0.0751 & $-0,297$ & 0.9920 & 1 & & & \\
Urbano ou rural & 0.1088 & 0,3005 & $-0,0462$ & $-0,0466$ & 1 & & \\
Sexo & 0,1171 & $-0,0848$ & -0.0166 & $-0,0177$ & -0.0764 & 1 & \\
Cor ou raça & 0,1525 & 0,1951 & 0,0396 & 0,0386 & 0,0383 & 0,009 & 1 \\
\hline
\end{tabular}

Fonte: Os autores (2018), com base em IBGE (2004; 2010).

\section{Sobre autores:}

Izete Pengo Bagolin: Economista. Doutora em Economia. Mestre em Economia Rural. Professora e pesquisadora do Programa de Pós-Graduação em Economia da Pontifícia Universidade Católica do Rio Grande do Sul (PPGE/PUC-RS). E-mail: izete.bagolin@pucrs.br, Orcid: http://orcid.org/0000-0003-4325-7677

Nelson Juarez Lewis Ferraz Neto: Economista pela Pontifícia Universidade Católica do Rio Grande do Sul (PUC-RS). Assistente fiscal na Timac Agro, Porto Alegre, RS. Discente em Ciências Contábeis. E-mail: nelson.jlfn@gmail.com, Orcid: http://orcid.org/0000-0001-9366-3935 